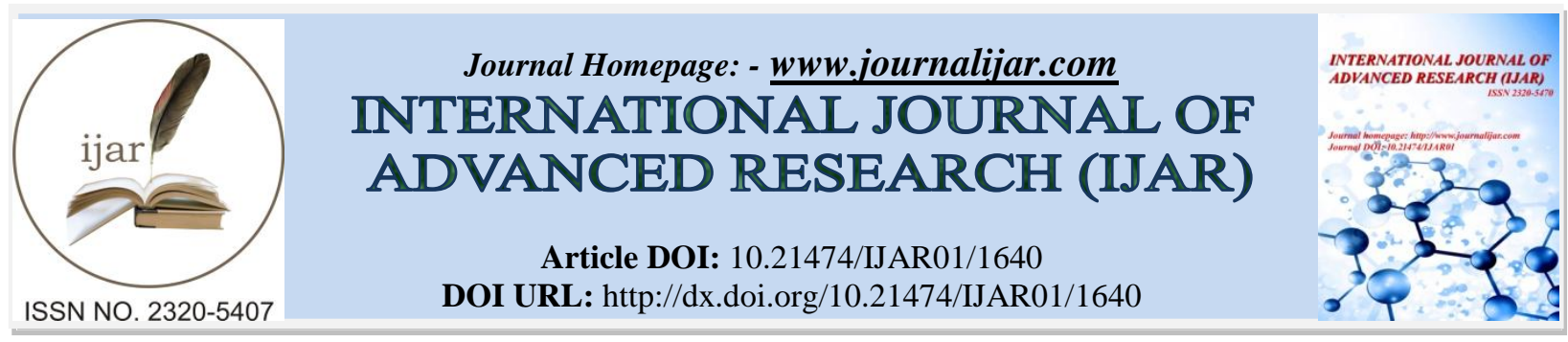

RESEARCH ARTICLE

\title{
A QUICK AND EASY METHOD FOR THE ISOLATION OF PERIPHERAL BLOOD MONONUCLEAR CELLS FROM WHOLE BLOOD BY DENSITY GRADIENT CENTRIFUGATION USING HISEP LSM MEDIUM.
}

\author{
Brahmaji Sontyana, Suresh Govatati and "Raghava Rao Tamanam. \\ Department of Biochemistry, Andhra University, Visakhapatnam, India.
}

\section{Manuscript Info \\ Manuscript History \\ Received: 12 July 2016 \\ Final Accepted: 23 August 2016 \\ Published: September 2016}

Key words:-

Peripheral blood mononuclear cells; Hisep LSM; density gradient; Tryphan blue

\begin{abstract}
Isolation of peripheral blood mononuclear cells (PBMCs) from whole blood is most commonly accomplished through density gradient centrifugation using density gradient solution such as ficoll paque. In this study, we describe a simple and rapid method for PBMC isolation using Hisep LSM as density gradient. High numbers of fully functional cells are obtained from whole blood and analyzed by flow cytometer and inverted microscope. The results of isolated PBMCs are reported in which the yield of cells are $3.6 \times 10^{6}$ cells $/ \mathrm{ml}$ with $98.92 \%$ viability by tryphan blue exclusion method and are $1.46 \times 10^{6} \mathrm{cells} / \mathrm{ml}$ with $95.35 \%$ viability by flow cytometric analysis. This technique is a convenient, quick, relatively simple, and inexpensive alternative to traditional PBMCs isolation techniques.
\end{abstract}

Copy Right, IJAR, 2016,. All rights reserved.

\section{Introduction:-}

Blood is a connective tissue and composed of blood cells and blood plasma. The blood cells consist of erythrocytes, leukocytes, and thrambocytes. Peripheral blood mononuclear cells (PBMCs) are blood cells with a round shaped nucleus, such as monocytes and lymphocytes. The lymphocyte population comprised of CD4 ${ }^{+}$and $\mathrm{CD} 88^{+} \mathrm{T}$-cells, Bcells and Natural Killer (NK) cells, CD14 ${ }^{+}$Monocytes, and Basophils/Neutrophils/Eosin-ophils/Dendritic cells. PBMCs are a critical component of the immune system, playing an integral role in the body's defenses. Isolation of PBMCs from whole blood is most commonly accomplished through density gradient centrifugation using density gradient solution such as ficoll paque (Boyum, 1968). In this study, we have used Hisep LSM medium for the isolation of PBMCs from whole blood.

Himedia's Hisep LSM is an iso-osmotic, low viscous medium containing polysucrose and sodium diatrizoate adjusted to a density of $1.0770 \pm 0.0010 \mathrm{~g} / \mathrm{ml}$. This reagent offers a quick and reliable process for simple isolation of human mononuclear cells and lymphocytes from defibrinated human blood. Hisep LSM is developed based on the earlier methods of lymphocyte isolation using centrifugation techniques (Boyum, 1964, 1968 and 1976) in which diluted defibrinated blood is layered on a solution of sodium diatrizoate and polysucrose and centrifuged at low speed for 30 minutes. Differential migration of cells during centrifugation results in the formation of layers containing different cell types (Bignold and Ferrante, 1987). The bottom layer contains erythrocytes, which have been aggregated by Hisep LSM and therefore sediment completely in the Hisep LSM density gradient media layer. Lymphocytes, monocytes, and platelets are not dense enough to penetrate into the Hisep LSM media layers having densities of $1.0770 \pm 0.0010 \mathrm{~g} / \mathrm{ml}$. These cells therefore collect as a concentrated band at the interface between the upper plasma layer and the Hisep LSM media layer. This banding enables the mononuclear cells to be recovered 
with high yield in a small volume with little mixing with the Hisep LSM media. Excess of platelets, Hisep LSM and plasma can then be removed by cell washing with isotonic phosphate buffered saline (PBS) and resulted cells suspended in RPMI medium.

The viability of PBMCs was assessed by flow cytometric analysis (Stewart and Stewart, 1994) and tryphan blue exclusion method (Lekshmi et al., 2012). Finally the resulting cell suspension then contains highly purified and mostly viable (98.92\%) PBMCs which can be widely used in both research and clinical laboratories .This procedure is a convenient, simple and inexpensive and also gives the better result of PBMCs isolation as like as the Ficoll paque density gradient process.

\section{Materials and Methods:-}

Reagents and equipment:-

DPBS, pH. 7.2 (Sigma, USA), Hisep LSM medium (Himedia, India), Defibrinated EDTA blood, RPMI-1640 medium (Himedia, India), Tryphan Blue (Himedia, India), $15 \mathrm{ml}$ centrifuge tubes , centrifuge with swinging bucket rotor (Remi R8C,India) and Viacount reagent (Merck Millipore, USA).

\section{Blood collection and sample preparation:-}

Peripheral blood $(5 \mathrm{ml})$ was obtained from healthy individuals (aged 18-24years) in EDTA coated vacutainer tubes. The anticoagulant treated blood was diluted with $2 \mathrm{X}$ volume of isotonic phosphate buffer saline (PBS) at $18^{0} \mathrm{C}$ to $20^{\circ} \mathrm{C}$.

\section{Preparation of buffy coat and PBMCs isolation:-}

Carefully layered $7.5 \mathrm{ml}$ of diluted blood sample over $2.5 \mathrm{ml}$ of Hisep LSM in a new $15 \mathrm{ml}$ centrifuge tube and centrifuged at $400 \mathrm{~g}$ for $30-40 \mathrm{~min}$ at $20^{\circ} \mathrm{C}$ in a swinging bucket rotor centrifuge. Using a sterile pipette, the upper layer containing plasma and platelets was removed without disturbing mononuclear cell layer at the interface. The layer of mononuclear cells was transferred to a sterile centrifuge tube using a sterile pipette. The transferred fraction, containing PBMC's, was washed with three volumes of DPBS at $400-500 \times \mathrm{g}$ for 10 to $15 \mathrm{~min}$ at $18^{\circ} \mathrm{C}$ to $20^{\circ} \mathrm{C}$. Aspirated the supernatant and pellet was again washed with DPBS at 400-500 $\times \mathrm{g}$ for 10-15 min. The supernatant was aspirated and resuspended the cell pellet in appropriate volume of media for further analysis. The cell viability and recovery was analyzed by using inverted microscope and flowcytometer as the methods described earlier (Holmes et al., 1999; Stewart and Stewart, 1994; Robinson, 1993; Givan, 1992).

\section{Cell viability assay:-}

Two viability assays were included for the screening of isolated PBMCs. These consisted of a standard tryphan blue stain for the assessment of cell membrane integrity, a commercial live/dead assay and cells were analyzed by inverted microscope. The latter assay used was the 'guava via counting stain' followed by flow cytometry analysis (Holmes et al., 1999).

\section{Tryphan blue analysis:-}

Cell viability was determined based on the trypan blue exclusion method. The PBMC's were washed twice with PBS, and resuspended. Each cell suspension $(0.1 \mathrm{ml})$ was mixed with $0.1 \mathrm{ml}$ trypan blue $(0.2 \%$ in PBS). After 1-2 min, each solution was place on a hemocytometer, and blue-stained cells were counted as nonviable. The percentage viability was calculated based on the percentage of unstained cells. The number of cells per $\mathrm{ml}$ was calculated by using the following formula-

Number of cells per $\mathrm{ml}=$ Average count per square $\times$ dilution factor $\times 10^{4}$

The percent of viable cells was calculated by the formula:

$\%$ viable cells $=($ no. of unstained cells $/$ total no. of cells $) \times 100$

\section{Flow cytometric analysis of PBMCs:-}

Flow cytometry analysis was carried out on a guava easy Cyte ${ }^{\mathrm{TM}}$ HT 3.1 equipped with blue laser (488 nm emission) and interfaced to Guavasoft ${ }^{\mathrm{TM}} 3.1 .1$ software. At least 10,000 cells per sample were analyzed and dot plots acquired were analyzed with Guavasoft ${ }^{\mathrm{TM}} 3.1 .1$ software of the guava easy Cyte ${ }^{\mathrm{TM}}$ HT 3.1 system. Gates were set to abort dead cells and debris and a dot plot was established to visualize the cells (Horvatinovich, et al., 1996). 


\section{Results:-}

Density gradient centrifugation of whole blood using Hisep LSM resulted in the characteristic separation of whole blood into 4 distinct layers from top to bottom: Hisep LSM density gradient, Plasma/platelets, PBMC, red blood cells/granulocytes (Fig 1).
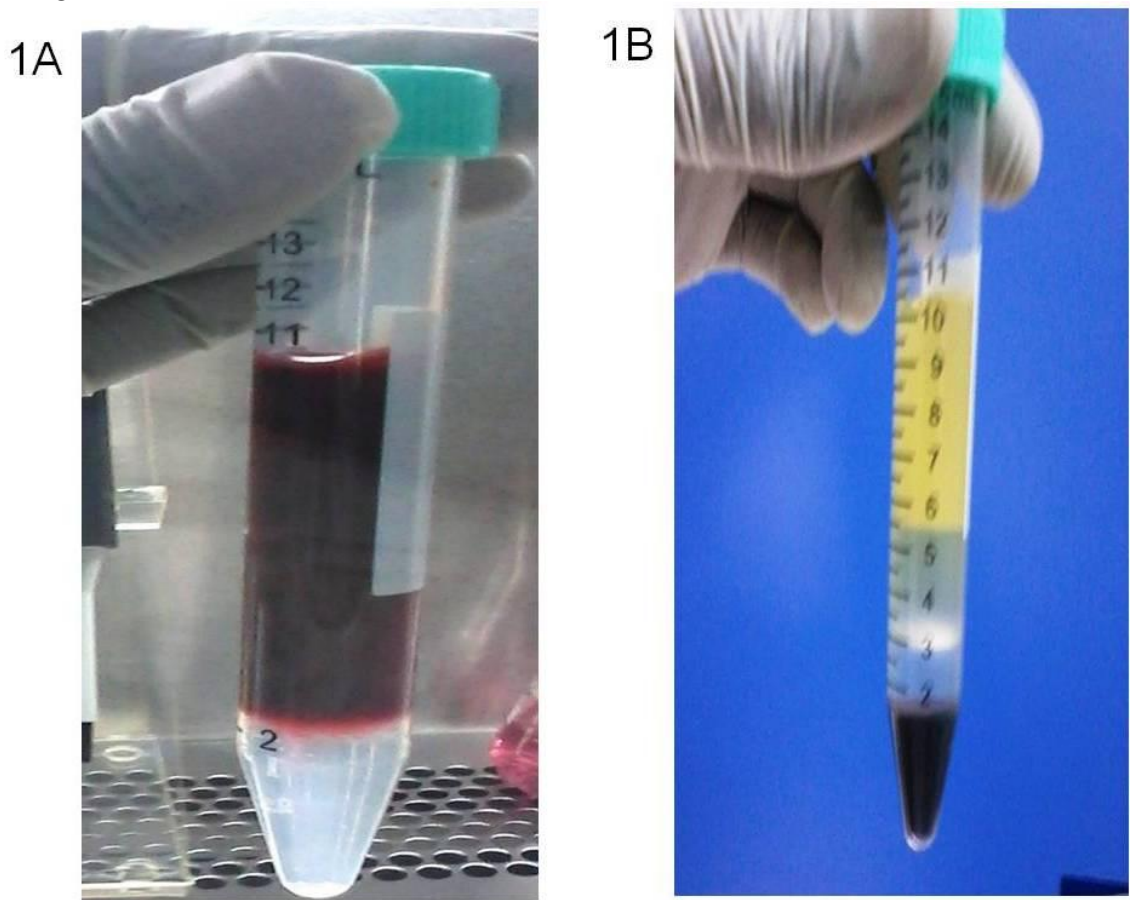

Figure 1:- A) Overlaying of blood sample on Hisep LSM medium. B) Four layers of blood sample: upper plasma layer, bottom erythrocyte layer and inerphase mononuclear cells over Hisep LSM after density gradient centrifugation.

\section{Cell yield and viability:-}

By tryphan blue exclusion method, we calculated the yield of PBMCs isolated by Hisep-LSM gradient centrifugation. The PBMC yield was $3.6 \times 10^{6}$ cells $/ \mathrm{ml}$. with $98.92 \%$ viability (Fig 2 )

Number of cells $=$ Average count per square $\times$ dilution factor $\times 10^{4}$

$$
\begin{aligned}
& =184 \times 2 \times 10^{4} \\
& =3.6 \times 10^{6} \text { cells } / \mathrm{ml} .
\end{aligned}
$$

$\%$ viable cells $=($ no. of stained cells $/$ total no. of cells $) \times 100$

$$
\begin{aligned}
& =(184 / 186) \times 100 \\
& =98.92 \%
\end{aligned}
$$
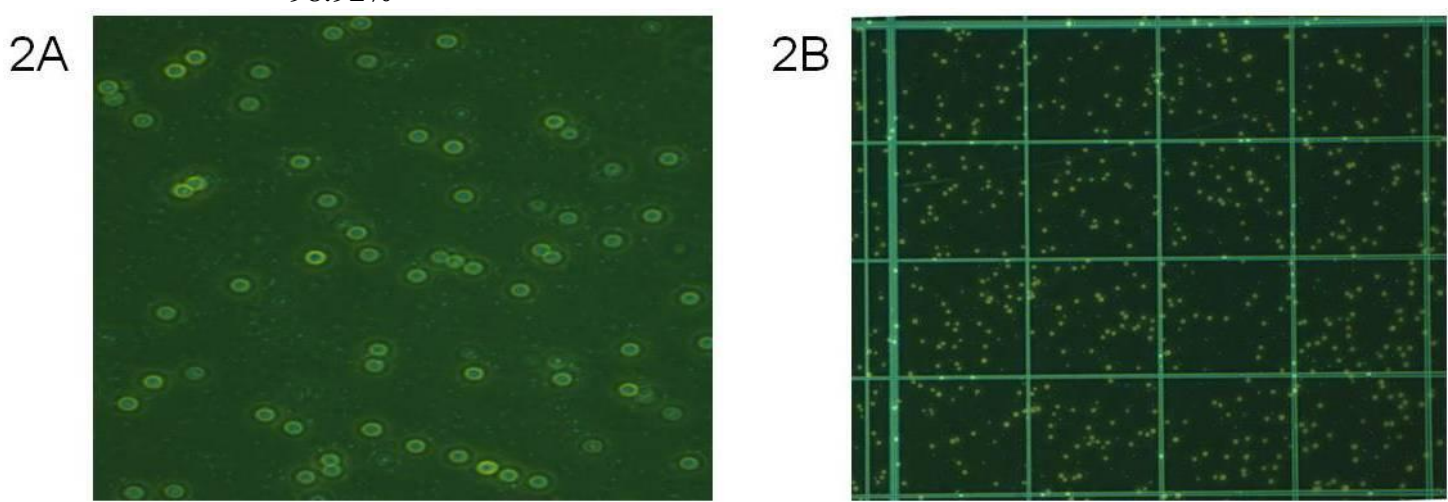

Figure 2:- A) Image of the PBMCs suspension in RPMI-1640 medium. B) Image of the PBMCs after treatment with tryphan blue under inverted microscope 
Dot plot based on the flow cytometric analysis of PBMCs are shown in Figure 3. The percentage of cell viability is $95.35 \%$ in manual reading and $96.49 \%$ in easy fit method (Table.1).
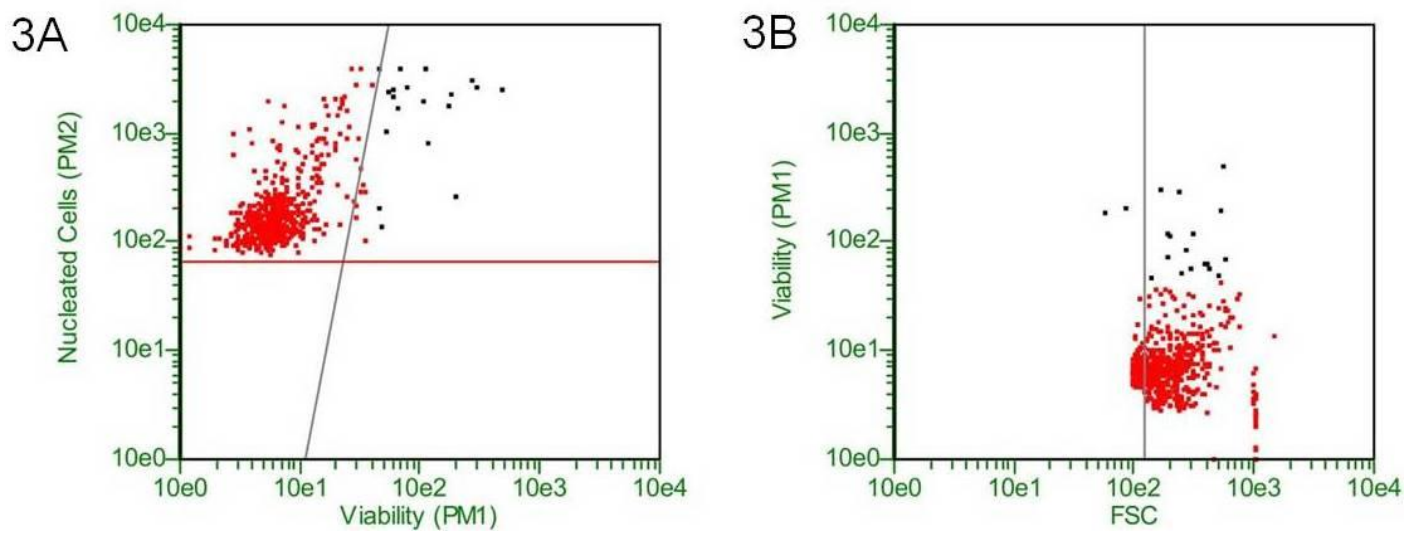

Figure 3:- Flowcytometric dot plots of isolated PBMCs: (A) Viability vs. nucleated cells dot plot with gating. The cells fall in domain of upper left was live cells. (B) Viability vs. FSC dot plot with gating. The cell present in right side was live ones.

Table 1:- Flow cytometric viacount assay of isolated PBMCs

\begin{tabular}{|c|c|c|c|c|}
\hline & \multicolumn{2}{|c|}{ EasyFit Results } & \multicolumn{2}{|c|}{ Manual Results } \\
\hline & Count & $\%$ of Total & Count & $\%$ of Total \\
\hline Viable & 522 & $96.49 \%$ & 492 & $95.35 \%$ \\
\hline \multirow[t]{2}{*}{ Dead } & 19 & $3.51 \%$ & 24 & $4.65 \%$ \\
\hline & Viable & Total & Viable & Total \\
\hline Cells / mL & $1.48 \mathrm{e} 05$ & $1.54 \mathrm{e} 05$ & $1.40 \mathrm{e} 05$ & $1.46 \mathrm{e} 05$ \\
\hline $\begin{array}{c}\text { Cells in } \\
\text { Org Sample }\end{array}$ & $1.48 \mathrm{e} 06$ & $1.54 \mathrm{e} 06$ & $1.40 \mathrm{e} 06$ & $1.46 \mathrm{e} 06$ \\
\hline Debris Index & \multicolumn{2}{|c|}{$59.48 \%$} & \multicolumn{2}{|c|}{$61.35 \%$} \\
\hline \multicolumn{2}{|c|}{ Particle Count } & Flow Information & & \\
\hline \multicolumn{2}{|c|}{ 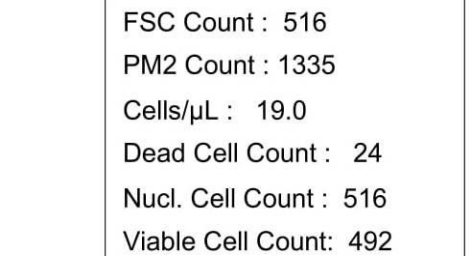 } & $\begin{array}{l}\text { Flow Rate : } \quad 0.59 \mu \mathrm{L} / \mathrm{s} \\
\text { Volume : } \quad 70.44 \mu \mathrm{L} \\
\text { Duration : } 01: 59 \mathrm{~m}: \mathrm{s}\end{array}$ & & \\
\hline
\end{tabular}

\section{Discussion:-}

Hisep LSM gradient centrifugation allows rapid and efficient isolation of peripheral blood mononuclear cells from defibrinated human blood sample (Niveditha et al., 2016). Himedia's Hisep LSM is an iso-osmotic, low viscous medium containing polysucrose and sodium diatrizoate adjusted to a density of $1.0770 \pm 0.0010 \mathrm{~g} / \mathrm{ml}$. We have used Hisep-LSM, the commercial preparation for the isolation of human peripheral blood cells from blood. This study briefly demonstrates that the Remi R-8C centrifuge with the swinging bucket rotor enables reliable and reproducible preparation of PBMCs by Hisep LSM density gradient. This method takes an advantage of the density differences between mononuclear cells and other elements found in the blood sample (Bignold and Ferrante, 1987). Mononuclear cells and platelets collect on top of the Hisep-LSM layer because they have a lower density; in contrast, red blood cells (RBC) and granulocytes have a higher density than Hisep-LSM and collect at the bottom of the Hisep-LSM layer (Fig 1b). Platelets are separated from the mononuclear cells by subsequent washing with PBS or by centrifugation through a fetal-bovine-serum (FBS) cushion gradient that allows penetration of mononuclear cells but not platelets. 
Trypan blue is a diazo dye which is used to selectively colour dead tissues or cells blue because it traverses the membrane in a dead cell. Live cells or tissues with intact cell membranes are not coloured because trypan blue is not absorbed. Hence, dead cells are shown as a distinctive blue colour under a microscope. On an average we counted PBMCs were $3.6 \times 10^{6}$ cells $/ \mathrm{ml}$ in isolated sample. The yield of viable cells was $98.92 \%$ by tryphan blue exclusion method.

The flow cytometric dot plot of PBMCs (Fig 3A) represents the relatedness between two parameters such as viability (PM1) and nucleated cells (PM2). This plot represents the percentage of viability of all nucleated cells. Both horizontal and vertical gates were set to abort dead cells and debris. All live cells fall in upper left region. The flow cytometric dot plot of PBMCs (Fig 3B) represents two parameters, forward scattering (FSC) on X-axis and viability (PM1) on Y-axis. Gate was set to abort dead cells and debris. The cells present in the left portion of the plot are dead cells and debris while the cells present in the right portion represents live cells.

A total of 516 cells were counted manually at a flow rate of $0.59 \mu 1 / \mathrm{s}$ and at cell count of $19 / \mu 1$. Out of 516 cell, 492 were live cells with $95.35 \%$ viability and remaining 24 were dead cells with $4.65 \%$. We also manually calculated the concentration of the cells was $1.46 \times 10^{6}$ cells. In easy fit method, we counted 541 cells in which 522 were live cells with $96.49 \%$ viability and $19(3.51 \%)$ were dead cells and also calculated the concentration of cells was $1.54 \times 10^{6}$ cells. Both the methods have given similar results. However, there is a small deviation with tryphan blue exclusion method. Cell viability in tryphan blue exclusion method $(98.92 \%)$ is fairly higher than viability in flow cytometeric analysis $(95.35 \%)$.

In conclusion, this Hisep LSM gradient is very favorable as like as the commonly used ficoll gradient media for enriching PBMCs. Both gradients have similar rate of yield of low density mononuclear cells. Hisep LSM ${ }^{\text {TM }}$ can be substituted for Ficoll-Paque ${ }^{\mathrm{TM}}$ without any need to change existing protocols. This method has proved very effective as a simple, quick and reliable process for enriching PBMCs which were analyzed by flow cytometer and tryphan blue exclusion method. Our data explores the efficacy of Hisep LSM for human PBMC isolation as well as the isolation of PBMC from other sources.

\section{Acknowledgements:-}

This work was funded by Science and Engineering Research Board (SERB/F/2149/2013-2014), Department of Science and Technology, Government of India. We would like to thank Prof. Satyanarayana Singh for trained me to culture the cells. We are also grateful to Prof. Hemalatha for providing flow cytometer instrument facility to do the work.

\section{References:-}

1. Bignold, L.P. and Ferrante, A. (1987): Mechanism of separation of polymorphonuclear leukocytes from whole blood by the one-step Hypaque-Ficoll method. J. Immunol. Meth., 96: 29-33.

2. Boyum, A. ( 1964): Seperation of white blood cells. Nature., 204: 793-794.

3. Boyum, A. ( 1968): Isolation of mononuclear cells and granulocytes from human blood. Scand. J. Clin. Lab. Invest., 21(97): 77-89.

4. Boyum, A. (1968): Isolation of leucocytes from human blood - further observations. (Paper II). Scand. J. Clin. Lab. Invest., 21(97): 31-50.

5. Boyum, A. (1976): Isolation of lymphocytes, granulocytes and macrophages. Scand J Immunol., 5: 9-15.

6. Givan, A.L. (1992): Flow Cytometry: First Principles. John Wiley \& Sons, Inc., New York.

7. Holmes, K., Fowlknes, B.J., Schmid, I. and Giorgi, J.V. (1999): Preparation of cells and reagents for Flow cytometry. In: Colign, JE, Kruisbeek, AM, Margulies, DH, Shevach, EM, Strober, W, (eds) Current Protocols in Immunology: Green Publishing and Wiley Inter Science, New York, 5.3.1.

8. Horvatinovich, J.M., Sparks, S.D. and Mann, K.P. (1996): Establishing a pure lymphocyte gate for the subset analysis by flow cytometry. Cytometry., 26(2): 172.

9. Lekshmi N., Geetha C.S. and Mohanan P.V. (2012): Detection of interleukin -1 $\beta$ from isolated human lymphocyte in response to lipopolysaccharide and lipoteichoic acid. Ind. J. Pharmacol., 44(6): 726-731.

10. Robinson, J.P. (1993): Handbook of Flowcytometry Methods, In: Wiley-Liss, New York.

11. Stewart, C.C. and Stewart, S.J. (1994): Methods in Cell Biology, Flow Cytometry, In: Wilson, L., Matsudaira, P.(Eds.), vol. 41,Second ed., Part A. Academic Press, London, pp. 52. 